See Article page 2499.

\section{Commentary: To ignore evil is to become an accomplice to it-predicting malignancy in mediastinal lymph nodes}

\author{
Luis F. Tapias, MD, and Daniela Molena, $\mathrm{MD}^{\mathrm{b}}$
}

The evaluation of mediastinal lymph nodes is perhaps the most critical step in the staging of patients with suspected or confirmed non-small cell lung cancer. Current national practice guidelines published by the National Comprehensive Cancer Network ${ }^{1}$ and the American College of Chest Physicians $^{2}$ recommend a noninvasive first step with computed tomography and positron emission tomography for all patients, followed by invasive mediastinal staging in patients with radiographic evidence of hilar or mediastinal lymph node involvement, or those with a radiographically normal mediastinum and central tumors $<3 \mathrm{~cm}$ or any tumor $>3 \mathrm{~cm}$ in size. In the absence of metastatic disease, results from mediastinal lymph node assessment directly impact subsequent treatment, which can range from surgery to definitive chemoradiation followed by immune checkpoint inhibition. ${ }^{3}$ The stakes are high when such different treatment strategies depend on this crucial step. Endobronchial ultrasound (EBUS)-transbronchial needle aspiration has emerged as the preferred first-line method for invasive mediastinal staging, with excellent diagnostic performance and an extremely low complication rate. ${ }^{4}$ Technical recommendations on the methods of EBUS-transbronchial needle aspiration have been published in an attempt to maximize its diagnostic yield. ${ }^{5}$ However, in certain situations, a diagnosis remains elusive and these patients are thus recommended to undergo further tissue sampling.

In their study, Hylton and colleagues ${ }^{6}$ attempt to tackle

From the a Division of Thoracic Surgery, Massachusetts General Hospital, Boston, Mass; and ${ }^{\mathrm{b}}$ Thoracic Service, Department of Surgery, Memorial Sloan Kettering Cancer Center, New York, NY.

Disclosures: Authors have nothing to disclose with regard to commercial support.

Received for publication Dec 10, 2019; revisions received Dec 10, 2019; accepted for publication Dec 11, 2019; available ahead of print Jan 31, 2020.

Address for reprints: Daniela Molena, MD, 1275 York Ave, 8th floor, New York, NY, 10065 (E-mail: molenad@mskcc.org).

J Thorac Cardiovasc Surg 2020;159:2510-1

$0022-5223 / \$ 36.00$

Copyright (c) 2020 by The American Association for Thoracic Surgery

https://doi.org/10.1016/j.jtcvs.2019.12.064
Check for updates

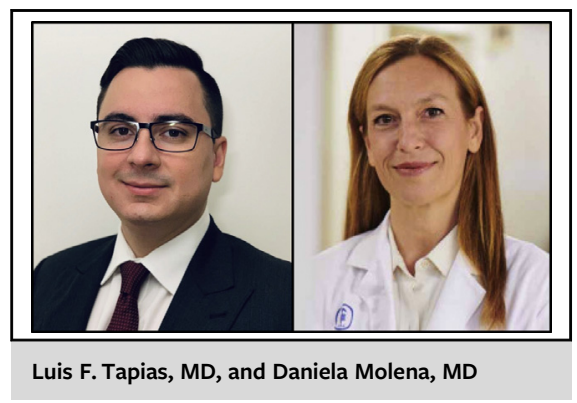

CENTRAL MESSAGE

Scores to predict malignancy in

mediastinal lymph nodes fall

short to justify avoiding a biopsy.

In reality, the major problem with

invasive mediastinal staging is

actually doing it.

this issue by proposing a scoring system to classify lymph nodes according to their predicted risk of harboring malignancy based exclusively on ultrasonographic features obtained by EBUS. Individual lymph nodes were assessed, and results were contrasted to the histopathologic evaluation of biopsies or resection specimens, which served as the gold standard to determine the presence of malignancy. Importantly, the authors identified 4 ultrasonographic features that were strongly associated with the presence of malignancy: size, absence of a central hilar structure, sharpness of the margins, and central necrosis. These features were included in a scoring system that performed fairly when predicting malignancy with a calculated biascorrected $\mathrm{C}$ statistic of 0.66 . Hylton and colleagues ${ }^{6}$ concluded that a cutoff of $\geq 3$ points (sensitivity: $31.5 \%$, specificity: $96.3 \%$ ) may be helpful when making decisions about repeated biopsy of a specific lymph node if the initial samples are inconclusive. The authors emphasize that the current standard of care is to biopsy lymph nodes in at least 3 nodal stations but introduce the idea of potentially using the proposed score to determine whether a lymph node should be biopsied at all. In a second part of their study, the authors demonstrated the efficacy of an online education module teaching health care providers how to score lymph nodes according to their ultrasonographic features, although with limited inter-rater agreement. 
There are limitations to this study that deserve mention. First, the ultrasonographic images were obtained by one person only, limiting reproducibility. Second, the authors failed to integrate important factors that are known to affect the probability of a mediastinal lymph node harboring malignancy, such as results from positron emission tomography/computed tomography, primary tumor size, and location. Furthermore, there was no acknowledgment of the conditional change in probability that arises when a lymph node (independent of its ultrasonographic features) is found to be malignant, as the presence of a positive mediastinal lymph node increases the likelihood of the presence of other positive mediastinal lymph nodes. ${ }^{1}$ Third, the authors did not apply other previously published methods to their population for a direct comparison to prove the superiority of their proposed method. Finally, and more troublesome, is the fact that the proposed scoring system misclassified 37 of $54(68.5 \%)$ lymph nodes with malignancy as "low risk." Therefore, the performance of the proposed method is not compelling enough to ignore the gold standard: obtaining a biopsy. Current guidelines recommend that tissue samples should always be obtained, independent of ultrasonographic features, as these are not reliable enough to forgo biopsy. ${ }^{5}$

The authors should be commended on their sound methodology and the precious infrastructure that they assembled to complete this work. This country-wide collaboration will prove fruitful in future studies. They have a strong foundation to build on their results to develop a more accurate and comprehensive prediction model for mediastinal lymph node malignant involvement. Such a score will likely prove useful in the clinic or in the operating room by streamlining the process of obtaining lymph node biopsies or deciding when to quit when the sample is persistently nondiagnostic, therefore, saving time and resources.

However, we strongly believe that the major problem with invasive mediastinal staging is actually doing it. Current recommendations for selection for invasive mediastinal staging have focused on being extremely sensitive to identify most patients with mediastinal nodal involvement, ${ }^{1,2}$ capturing up to $100 \%$ of patients with true mediastinal disease. ${ }^{7}$ However, a recent analysis of the Society of Thoracic Surgeons General Thoracic Surgery Database showed that $57 \%$ of patients with non-small cell lung cancer clinical stages IB to IIIA did not undergo invasive mediastinal staging. ${ }^{8}$ Ignoring the potential evil residing in the mediastinal lymph nodes results in suboptimal outcomes. Therefore, the real hurdle is getting surgeons and patients into the room to have the mediastinum sampled. Hopefully, noninvasive methods in the future will accurately predict the presence of malignancy in the mediastinum. Until then, we should enforce a sensitive strategy to select patients for invasive mediastinal staging, always sampling nodes, even if that means sampling several benign lymph nodes.

\section{References}

1. National Comprehensive Cancer Network. Non-small cell lung cancer (Version 1.2020). 2020. Available at: https://www.nccn.org/professionals/physician_gls/ pdf/nscl.pdf. Accessed December 1, 2019

2. Silvestri GA, Gonzalez AV, Jantz MA, Margolis ML, Gould MK, Tanoue LT, et al Methods for staging non-small cell lung cancer: diagnosis and management of lung cancer, 3rd ed: American College of Chest Physicians evidence-based clinical practice guidelines. Chest. 2013;143(5 suppl):e211S-50S.

3. Antonia SJ, Villegas A, Daniel D, Vicente D, Murakami S, Hui R, et al. Overall survival with durvalumab after chemoradiotherapy in stage III NSCLC. $N$ Engl J Med. 2018;379:2342-50.

4. Yasufuku K, Pierre A, Darling G, De Perrot M, Waddell T, Johnston M, et al. A prospective controlled trial of endobronchial ultrasound-guided transbronchial needle aspiration compared with mediastinoscopy for mediastinal lymph node staging of lung cancer. J Thorac Cardiovasc Surg. 2011;142:1393-400.e1.

5. Wahidi MM, Herth F, Yasufuku K, Shepherd RW, Yarmus L, Chawla M, et al. Technical aspects of endobronchial ultrasound-guided transbronchial needle aspiration: CHEST Guideline and Expert Panel Report. Chest. 2016;149:816-35.

6. Hylton DA, Turner S, Kidane B, Spicer J, Xie F, Farrokhyar F, et al. The Canada Lymph Node Score for prediction of malignancy in mediastinal lymph nodes during endobronchial ultrasound. J Thorac Cardiovasc Surg. 2020;159: 2499-507.e3.

7. Verdial FC, Madtes DK, Hwang B, Mulligan MS, Odem-Davis K, Waworuntu R, et al. Prediction model for nodal disease among patients with non-small cell lung cancer. Ann Thorac Surg. 2019;107:1600-6.

8. Krantz SB, Howington JA, Wood DE, Kim KW, Kosinski AS, Cox ML, et al. Invasive mediastinal staging for lung cancer by The Society of Thoracic Surgeons Database participants. Ann Thorac Surg. 2018;106:1055-62. 